\title{
Novel Lanthanide Luminescent Materials Based on Complexes of 3-Hydroxypicolinic Acid and Silica Nanoparticles
}

\author{
Paula C. R. Soares-Santos, ${ }^{\dagger}$ Helena I. S. Nogueira, ${ }^{\dagger}$ Vitor Félix, $^{\dagger}$ \\ Michael G. B. Drew, ${ }^{\S}$ Rute A. Sá Ferreira, ${ }^{\ddagger}$ Luís D. Carlos, ${ }^{*, \ddagger}$ and \\ Tito Trindade*,† \\ Departments of Chemistry and Physics, University of Aveiro, \\ CICECO, 3810-193 Aveiro, Portugal, and Department of Chemistry, \\ University of Reading, Whiteknights, Reading UK RG6 6AD
}

Received April 15, 2002. Revised Manuscript Received October 9, 2002

\begin{abstract}
N ew lanthanide complexes of 3-hydroxypicolinic acid ( $\mathrm{H}$ picOH ) were prepared: [ $\mathrm{Ln}\left(\mathrm{H}_{2} \mathrm{O}\right)$ $(\text { picOH })_{2}(u-\mathrm{H}$ picO $\left.)\right] \cdot 3 \mathrm{H}_{2} \mathrm{O}(\mathrm{Ln}=\mathrm{Eu}, \mathrm{Tb}, \mathrm{Er})$. The complexes were characterized using photoluminescence, infrared, Raman, and ${ }^{1} \mathrm{H}$ NMR spectroscopy, and elemental analysis. The crystal structure of $\left[\mathrm{Eu}\left(\mathrm{H}_{2} \mathrm{O}\right)(\mathrm{picOH})_{2}(\mu-\mathrm{H}\right.$ picO) $] \cdot 3 \mathrm{H}_{2} \mathrm{O} \mathbf{1}$ was determined by X-ray diffraction. Compound $\mathbf{1}$ crystallizes in a monoclinic system with space group P $21 / c$ and cell parameters $a=9.105(13) \AA, b=18.796(25) \AA$, and $c=13.531(17) \AA$, and $\beta=104.86(1)$ deg. The 3-hydroxypicolinate ligands coordinate through both $\mathrm{N}, \mathrm{O}$ - or $\mathrm{O}, \mathrm{O}$ - chelation to the lanthanide ions, as shown by X-ray and spectroscopic results. Photoluminescence measurements were performed for the $\mathrm{Eu}(\mathrm{III})$ and $\mathrm{Tb}(\mathrm{III})$ complexes; the $\mathrm{Eu}(\mathrm{III})$ complex was investigated in more detail. The Eu(III) compound is highly luminescent and acts as a photoactive center in nanocomposite materials whose host matrixes are silica nanoparticles.
\end{abstract}

\section{Introduction}

In recent years there has been intense research on the synthesis of photoactive lanthanide complexes. ${ }^{1-3}$ The possibility of having ligands in such species that function as light-harvesting units has been investigated. These units can act as antennas for collecting light and transferring the energy to the lanthanide, originating extensive photoluminescence. ${ }^{4}$ Coordination compounds of this type may be regarded as photoactive units to fabricate novel optical materials, namely as luminescent centers in host matrixes.

Trivalent lanthanide ions form stable coordination complexes with a variety of organic ligands.5,6 Lanthanide compl exes with ligands containing nitrogen and oxygen donors have been investigated (ethylenediaminetetracetate and its derivatives ${ }^{5}$ are good ex-

* Authors to whom correspondence should be addressed. Dr. Luís António Dias Carlos: phone 351-234-370946; fax 351-234-424965, e-mail Icarlos@fis.ua.pt. Dr. Tito Trindade: phone 351-234-370726; fax 351-234-370084; e-mail ttrindade@dq.ua.pt.

+ Department of Chemistry, University of Aveiro.

₹ Department of Physics, University of Aveiro.

$\S$ University of Reading.

(1) Arnaud, N.; Vaquer, E.; Georges, J . TheAnalyst 1998, 123, 261.

(2) Sá, G. F.; Malta, O. L.; Donegá, C. M.; Simas, A. M.; Longo R. L.; Santa-Cruz, P. A.; Silva, E. F., J r. Coord. Chem. Rev. 2000, 196, 165.

(3) Vicentini, G.; Zinner, L. B.; Zukerman-Schpector, J .; Zinner, K. Coord. Chem. Rev. 2000, 196, 353.

(4) Lianshe, F.; Qingguo, M.; Hongiie, Z.; Shubin, W.; Kuiyue, Y.; J iazuan, N. J . Phys. Chem. Solids 2000, 61, 1877.

(5) Hart, F. A. Scandium, Yttrium and the Lanthanides. In Comprehensive Coordination Chemistry; Wilkinson, G., Gillard, R. D. McCleverty, J . A., Eds.; Pergamon Press: Elmsford, NY, 1987; Vol. 3, p 1059. 3613. amples), in particular for aromatic ligands such as picolinate, ${ }^{7}$ dipicol inates, ${ }^{8-10}$ 2,2'-bipyridine-6,6'-dicarboxylic acid ${ }^{11}$ and bis-pyridones, ${ }^{12}$ to mention just a few. The latter constitute a very interesting type of complexes, because energy transfer from the aromatic groups close to the lanthanide ions may considerably enhance the luminescence efficiency of the ion. For example, it has been reported that $\mathrm{Tb}(\mathrm{III})$ luminescence is enhanced more than 104-fold by dipicolinic acid. .10 The ligand 3-hydroxypicolinic acid ( $\mathrm{HpiCOH})$, used in the present work, is a potential chelate with interesting possibilities, such as $\mathrm{N}, \mathrm{O}$-chelation (of the monodeprotonated ligand, $\mathrm{picOH}^{-}$, through the pyridinic nitrogen and the carboxylate group, forming a fivemembered chelate ring) or O,O-chelation (through the carboxylate group and the deprotonated hydroxyl group, forming a six-membered chelate ring; either of the twice deprotonated ligand, $\mathrm{picO}^{2-}$, or, as found in this work, of the monodeprotonated $\mathrm{HpicO}^{-}$ligand with a protonated pyridinic nitrogen) as shown in Scheme 1.

Here, the synthesis of the lanthanide complexes $\left[\mathrm{Ln}\left(\mathrm{H}_{2} \mathrm{O}\right)(\mathrm{picOH})_{2}(u-\mathrm{H}\right.$ pi cO $\left.)\right] \cdot 3 \mathrm{H}_{2} \mathrm{O}(\mathrm{Ln}=\mathrm{Eu} \mathrm{1}, \mathrm{Tb} \mathbf{2}, \mathrm{Er}$ 3) is reported with their characterization using vibrational and NMR spectroscopies. The chelation modes of

(7) Park, Y. J .; Lee, B. H.; Kim, W. H.; Do, Y. J . Colloid Interface Sci. 1999, 209, 268.

(8) Albertsson, J. Acta Chem. Scand. 1970, 24, 1213.

(9) Barela, T. D.; Sherry, A. D. Anal. Biochem. 1976, 71, 351.

(10) Lamture, J . B.; Zhou, Z. H.; Kumar, A. S.; Wensel, T. G. Inorg Chem. 1995, 34, 864.

(11) Bünzli, J . G.; Charbonnière, L. J .; Ziessel, R. F. J . Chem. Soc., Dalton Trans. 2000, 1917.

(12) Goodgame, D. M. L.; Hill, S. P. W.; Smith, A. M.; Williams, D. J. J . Chem. Soc., Dalton Trans. 1994, 859. 


\section{Scheme 1}<smiles>O=C1O[Te]Oc2cccnc21</smiles><smiles>O=C1O[Al]2C=CC=C(O)C12</smiles>

$\mathrm{O}, \mathrm{O}$-chelation ( $\mathrm{HpicO}^{-}$ligand) $\mathrm{N}, \mathrm{O}$-chelation ( $\mathrm{picOH}^{-}$ligand)

the ligand to the different lanthanides is discussed on the basis of the X-ray crystal structure of $\left[\mathrm{Eu}\left(\mathrm{H}_{2} \mathrm{O}\right)\right.$ $\left.(\text { picOH })_{2}(\mu-\mathrm{H} \mathrm{picO})\right] \cdot 3 \mathrm{H}_{2} \mathrm{O} \mathbf{1}$ and spectroscopic results, and compared to published data for analogous compounds of d-transition metals. ${ }^{13-16}$ The 3-hydroxypicolinate ligands show both N,O- and O,O- chelation in the crystal structure of the E U(III) complex 1; spectroscopic data are consistent with the $\mathrm{Tb}(\mathrm{III})$ and $\mathrm{Er}(\mathrm{III}) \mathrm{com}$ plexes, $\mathbf{2}$ and $\mathbf{3}$ respectively, having the same type of coordination. The local environment of the lanthanide ions in these compounds is further discussed on the basis of their luminescence properties.

There has been great interest in devel oping luminescent nanomaterials for applications in the optoelectronic ${ }^{17,18}$ and biodetection fields. ${ }^{19}$ Size-tuned semiconducting nanocrystals (e.g., IINI semiconductors) have been investigated in some detail. ${ }^{17-20}$ The strategy reported here involves using another type of material to fabricate novel luminescent nanomaterials via a lowtemperature processing method. In fact, it was found that the $E$ u(III) complex $\mathbf{1}$ is easily dispersed in a silica network. Nanoparticles of $\mathbf{1} / \mathrm{SiO}_{2}$ were prepared by a sol-gel method. For the Eu(III) complex $\mathbf{1}$ and the hybrid derivative $\mathbf{1} / \mathrm{SiO}_{2}$, a detailed analysis on the luminescence properties was carried out and is presented here.

\section{Experimental Section}

All chemicals were supplied by Aldrich and used as received. Preparation of $\left[\mathrm{Ln}\left(\mathrm{H}_{2} \mathrm{O}\right)(\mathrm{picOH})_{2}(\mu-\mathrm{HpicO})\right] \cdot 3 \mathrm{H}_{2} \mathrm{O}(\mathrm{Ln}$ $=\mathbf{E u ~ 1 , ~ T b ~ 2 , ~ E r ~ 3 ) . ~} \mathrm{Ln}(\mathrm{OH})_{3}(\mathrm{Ln}=\mathrm{Eu}, \mathrm{Tb}, \mathrm{Er})$ starting compounds were prepared by adding aqueous solutions $(8 \mathrm{~mL})$ of $\mathrm{KOH}(4.5 \mathrm{mmol})$ to an equal volume of aqueous solutions containing the lanthanide chloride salt $(1.5 \mathrm{mmol})$. The solid formed was stirred over $90 \mathrm{~min}$, filtered, and washed thoroughly with distilled water.

The 3-hydroxypicolinate Ianthanide complexes were prepared similarly. Typically, $1 \mathrm{mmol}$ of $\mathrm{Ln}(\mathrm{OH})_{3}$ was added to an aqueous solution ( $25 \mathrm{~mL}$ ) containing 3-hydroxypicolinic acid (4 mmol). This mixture was stirred during $1 \mathrm{~h}$, then heated for $30 \mathrm{~min}$ at $80^{\circ} \mathrm{C}$, and further stirred over $8 \mathrm{~h}$ at room

(13) Quintal, S. M. O.; Nogueira, H. I. S.; Félix, V.; Drew, M. G. B. New J. Chem. 2000, 24, 511.

(14) Quintal, S. M. O.; Nogueira, H. I. S.; Carapuça, H. M.; Félix, V.; Drew, M. G. B. J . Chem. Soc., Dalton Trans. 2001, 3196.

(15) Griffith, W. P.; Nogueira, H. I. S.; Parkin, B. C.; Sheppard, R. N.; White, A. J . P.; Williams, D. J . J . Chem. Soc., Dalton Trans. 1995 1775.

(16) Edwards, C. F.; Griffith, W. P.; White, A.J . P.; Williams, D. J. J . Chem. Soc., Dalton Trans. 1993, 3813.

(17) Nirmal, M.; Dabbousi, B. O.; Bawendi, M. G.; Macklin, J J J .; Trautman, J. K.; Harris, T. D.; Brus, L. E. Nature 1996, 383, 802.

(18) Klein, D. L.; Roth, R.; Lim, A. K. L.; Alivisatos, A. P.; McEuen,

P. L. Nature 1997, 389, 699.

(19) Bruchez, M., J r.; Moronne, M.; Gin, P.; Weiss, S.; Alivisatos, A. P. Science 1998, 281, 2013.

(20) Trindade, T.; O'Brien, P.; Pickett, N. L. Chem. Mater. 2001 13, 3843. temperature. The solid obtained was filtered, washed thoroughly with distilled water, and dried over silica gel. Single crystals of $\left[\mathrm{Eu}\left(\mathrm{H}_{2} \mathrm{O}\right)(\mathrm{picOH})_{2}(u-\mathrm{H}\right.$ picO $\left.)\right] \cdot 3 \mathrm{H}_{2} \mathrm{O} \mathbf{1}$ were obtained from the filtrate after sl ow evaporation for two months.

Preparation of $\mathrm{SiO}_{2}$ Nanocomposites. The E u(III) complex $\mathbf{1}$ was dispersed within a silica matrix using a sol-gel method adapted from the Stöber method. ${ }^{21}$

Tetraethoxysilane (TEOS, $0.32 \mathrm{~mL}$ ) was added to $1 \mathrm{~mL}$ of absolute ethanol, followed by the addition of a DMSO solution $(0.33 \mathrm{~mL})$ containing complex $\mathbf{1}(10.5 \mathrm{mg})$. The alkoxide hydrolysis was promoted by addition of $2 \mathrm{~mL}$ of distilled water to the previous solution. This mixture was allowed to stand over a few days until a rigid gel was formed. The gel was then dried in a oven at $60{ }^{\circ} \mathrm{C}$ leading to solid pieces of a $\mathbf{1} / \mathrm{SiO}_{2}$ composite material ( $\mathrm{Eu} / \mathrm{SiO}_{2}$ composite $\left.\mathbf{A}\right)$.

When the alkoxide hydrolysis was catalyzed by adding a $\mathrm{NH}_{4} \mathrm{OH}$ solution (25\%) instead of water, nanoparticles of the $\mathbf{1} / \mathrm{SiO}_{2}$ composite material $\left(\mathrm{Eu} / \mathrm{SiO}_{2}\right.$ composite $\left.\mathbf{B}\right)$ were obtained. TEOS $(0.78 \mathrm{~mL})$ was added to a mixture of absolute ethanol $(5 \mathrm{~mL})$ and distilled water $(0.06 \mathrm{~g})$. This mixture was allowed to stand over $30 \mathrm{~min}$ followed by the addition of a DMSO solution (2 mL) containing complex 1 (27.9 mg); finally, $2 \mathrm{~mL}$ of $\mathrm{NH}_{4} \mathrm{OH}$ solution (25\%) was added. On standing for $30 \mathrm{~min}$, the colloid was filtered and washed thoroughly with distilled water $\left(\mathrm{Eu} / \mathrm{SiO}_{2}\right.$ composite $\left.\mathbf{B}\right)$.

Instrumentation. Infrared spectra were measured as $\mathrm{KBr}$ disks using a Mattson $7000 \mathrm{FT}$ instrument. Raman spectra were recorded using a Brüker RF S100/S FT-Raman spectrometer ( $\mathrm{Nd}$ :Y AG laser, $1064 \mathrm{~nm}$ excitation). ${ }^{1} \mathrm{H}$ NMR spectra were recorded using a Brüker $A M X 300$ spectrometer $\left({ }^{1} \mathrm{H}, 300 \mathrm{M} \mathrm{Hz}\right.$; $\left.{ }^{13} \mathrm{C}, 75.4 \mathrm{MHz}\right)$ referenced to $\mathrm{Si}\left(\mathrm{CH}_{3}\right)_{4}$ or the solvent. Microanalyses $(\mathrm{C}, \mathrm{H}$, and $\mathrm{N})$ were measured in the Department of Chemistry, University of Aveiro, and the lanthanide content in the complexes was measured by ICP (Analytical Laboratories, University of Aveiro).

Room-temperature photoluminescence spectra were re corded on a J obin Yvon-Spex spectrometer (HR 460) coupled to a R928 Hamamatsu photomultiplier. An He-Cd laser beam ( $325 \mathrm{~nm}$ and $\mathrm{P}=30 \mathrm{~mW}$ ) and a $150 \mathrm{~W}$ Xe arc lamp coupled to a excitation monochromator J obin Y von - Spex (TRIAX 180) were used as excitation sources. All the spectra were corrected for the response of the detector. The lifetime measurements were carried out using a pulsed Xe arc lamp ( $5 \mathrm{~m}$ / /pulse, $3 \mu \mathrm{s}$ bandwidth) coupled to a Kratos GM-252 monochromator and a Spex 1934 C phosphorimeter.

The X-ray powder diffraction (XRD) patterns were recorded using a Philips instrument operating with $\mathrm{Cu} K \alpha$ radiation $(\lambda$ $=1.54178 \AA$ ) at $40 \mathrm{kV} / 50 \mathrm{~mA}$. Scanning electron microscopy (SEM) images were obtained using a FEG-SEM Hitachi S4100 microscope operating at $25 \mathrm{kV}$. The samples were prepared by deposition of an aliquot of an ethanol suspension of the sample on aluminum pieces and then coated with evaporated carbon.

Crystallography. Single crystals of $\mathbf{1}$ were obtained by slow evaporation from an aqueous solution of the complex at room temperature. The crystal data and refinement details are given in Table 1.

$X$-ray data were measured using MAR research image plate system using a graphite-monochromated Mo K $\alpha$ radiation $(\lambda$ $=0.71073 \AA$ ) at $\approx 295 \mathrm{~K}$. The selected crystal mounted in a glass capillary under saturated solvent atmosphere was positioned at $70 \mathrm{~mm}$ from the plate. In total, 95 frames were taken at $2^{\circ}$ intervals using a counting time adequate to the crystal diffraction pattern. Data analysis was performed with the XDS program. ${ }^{22}$ An empirical absorption correction was applied to intensities of $\mathbf{1}$, using a version of the DIFABS program modified for image plate geometry. ${ }^{23}$

Intensities of 5766 observations were collected, of which 3243 were independent reflections giving a $R_{\text {int }}$ of 0.0290 . The

(21) Stöber, W.; Fink, A.; Bohn, E. J . Colloid Interface Sci. 1968, $26,62$.

(22) Kabsch, W. J. Appl. Crystallogr. 1988, 21, 916.

(23) Walker, N.; Stuart, D. DIFABS, Acta Crystallogr., Sect. A 1983, 39, 158. 
Table 1. Crystallographic Data for $\left[\mathrm{Eu}(\mathrm{picOH})_{3}\left(\mathrm{H}_{2} \mathrm{O}\right)\right] \cdot 3 \mathrm{~h}_{2} \mathrm{O} \mathbf{1}$

\begin{tabular}{ll}
\hline formula & $\mathrm{C}_{18} \mathrm{H}_{20} \mathrm{EuN}_{3} \mathrm{O}_{13}$ \\
$\mathrm{M}$ & 638.33 \\
crystal system & monoclinic \\
space group & $\mathrm{P} 21 / \mathrm{c}$ \\
$\mathrm{a}(\AA)$ & $9.105(13)$ \\
$\mathrm{b}(\AA)$ & $18.796(25)$ \\
$\mathrm{C}(\AA)$ & $13.531(17)$ \\
$\beta($ deg $)$ & $104.86(1)$ \\
$\mathrm{V} / \AA^{3}$ & $2238(5)$ \\
$\mathrm{Z}$ & 4 \\
$\mathrm{D}_{\text {calcd }} / \mathrm{gcm}^{-3}$ & 1.894 \\
$\mu\left(\mathrm{mm}^{-1}\right)$ & 2.877 \\
$\mathrm{~F}(000)$ & 1264 \\
final $\mathrm{R}$ indices $[\mathrm{I}>2 \sigma(\mathrm{I})]$ & \\
$\mathrm{R}_{1}$ and $\mathrm{wR}_{2}{ }^{\mathrm{a}}$ & $0.0348,0.0906$ \\
$\mathrm{R}$ indices $($ all data $)$ & \\
$\mathrm{R}_{1}$ and $\mathrm{wR}_{2}$ & $0.0483,0.0978$ \\
&
\end{tabular}

${ }^{a} \mathrm{R}_{1}=\sum(\Delta \mathrm{F}) / \sum\left(\mathrm{F}_{\mathrm{o}}\right), \quad \mathrm{wR}_{2}=\left\{\sum\left[\mathrm{w} \Delta\left(\mathrm{F}^{2}\right)^{2}\right] / \Sigma\left[\mathrm{w}\left(\mathrm{F}_{\mathrm{o}}{ }^{2}\right)^{2}\right]\right\}^{1 / 2}, \mathrm{w}=$ $\left.1 / \sigma^{2}\left(\mathrm{~F}_{0}^{2}\right)+(0.0528 \mathrm{P})+6.0222 \mathrm{P}\right]$, where $\mathrm{P}=\left(\operatorname{Max}\left(\mathrm{F}_{0}^{2}, \theta\right)+2 \mathrm{~F}_{c}{ }^{2}\right) /$ 3. This material is available free of charge via the Internet at http://pubs.acs.org. ${ }^{2}$

structure was solved by direct methods and subsequent difference F ourier syntheses, and refined by full-matrix leastsquares refinement method on $F^{2}$ using the SHELX97 software package. ${ }^{24}$ Anisotropic displacements were refined for all non-hydrogen atoms. Hydrogen atoms bonded to carbon atoms were introduced in the refinement at idealized geometric positions given thermal isotropic parameters equivalent to 1.2 times those of the atom to which they are attached. The positions of the hydrogen atoms of water molecules, of the two phenol groups, and as well as the pyridine $\mathrm{N}-\mathrm{H}$ group, were discernible from difference Fourier maps. The first ones were introduced in the refinement assuming $\mathrm{O}-\mathrm{H}$ distances and angles $\mathrm{H}-\mathrm{O}-\mathrm{H}$ constrained to $0.82 \AA$ and $104.5^{\circ}$, respectively, wher eas for the second ones only the restraint on the distance was applied. The $\mathrm{N}-\mathrm{H}$ group was refined with a distance constrained to $0.89 \AA$. The thermal motion of these hydrogen atoms was described using individual thermal isotropic parameters. The final refinements of 352 parameters converged to $R_{1}$ and $w R_{2}$ values quoted in Table 1 . The final residual electronic density in $\Delta \mathrm{F}$ map, in the range 1.19 to $-0.91 \mathrm{e} / \AA^{-3}$, was within the expected values. The ORTEP plot and crystal packing diagram were drawn with the PLATON program, ${ }^{25}$ whereas the diagram of the polyhedra chain was performed using WE BLAB VIEWER software. ${ }^{26}$

\section{Results and Discussion}

Preparation of Lanthanide(III) 3-Hydroxypicolinate Complexes. Suspensions of $\mathrm{Ln}(\mathrm{OH})_{3}$ $(\mathrm{Ln}=\mathrm{Eu}, \mathrm{Tb}, \mathrm{Er})$ and $\mathrm{HpicOH}$ in aqueous solutions were stirred for $9 \mathrm{~h}$ to give a series of $\mathrm{Ln}$ complexes with the 3-hydroxypicolinate ligand. The solid product obtained from each preparation was filtered off and washed thoroughly with distilled water. Elemental analysis results (Table 4$)$ are in accordance with the molecular formula [ $\mathrm{Ln}\left(\mathrm{H}_{2} \mathrm{O}\right)(\mathrm{picOH})_{2}\left(u-\mathrm{H}\right.$ picO)] $3 \mathrm{H}_{2} \mathrm{O}$ for all the complexes ( $\mathrm{Ln}=\mathrm{Eu} \mathrm{1}, \mathrm{Tb} \mathbf{2}, \mathrm{Er} \mathbf{3})$ as shown in the crystal structure of $\mathbf{1}$, which is consistent with the spectroscopic data presented below.

Crystal Structure of $\left[\mathrm{Eu}\left(\mathrm{H}_{2} \mathrm{O}\right)(\mathrm{picOH})_{2}(\mu-\mathrm{HpicO})\right]$. $\mathbf{3 H}_{\mathbf{2}} \mathbf{O} \mathbf{1}$. The asymmetric unit of $\mathbf{1}$ is composed of a $\left[\mathrm{Eu}\left(\mathrm{H}_{2} \mathrm{O}\right)(\mathrm{picOH})_{2}(\mu-\mathrm{H}\right.$ picO $\left.)\right]$ complex and three water

(24) Sheldrick, G. M. SHELXS-86, Acta Crystallogr., Sect. A 1990, 46, 467; Sheldrick, G. M. SHELX-97, University of Göttingen, 1997.

(25) Spek, A. L. PLATON, a Multipurpose Crystallographic Tool; Utrecht University: Utrecht, The Netherlands, 1999.

(26) WEBLAB VIEWER, version 2.01; Molecular Simulations, Inc.: San Diego, CA, 1997.
Table 2. Selected Bond Lengths $(\AA)$ and Angles (deg) for 1

\begin{tabular}{|c|c|c|c|}
\hline $\begin{array}{l}\mathrm{u}-\mathrm{O}(331) \\
\mathrm{u}-\mathrm{O}(100) \\
\mathrm{u}-\mathrm{O}(371) \\
\mathrm{u}-\mathrm{N}(21)\end{array}$ & $\begin{array}{l}2.309(4) \\
2.389(4) \\
2.393(4) \\
2.578(5)\end{array}$ & $\begin{array}{l}\mathrm{Eu}-\mathrm{O}(171) \\
\mathrm{Eu}-\mathrm{O}(372)^{\mathrm{a}} \\
\mathrm{Eu}-\mathrm{O}(271) \\
\mathrm{Eu}-\mathrm{N}(11)\end{array}$ & $\begin{array}{l}2.373(4) \\
2.390(4) \\
2.410(4) \\
2.596(5)\end{array}$ \\
\hline $\begin{array}{l}(331)-E u-O(171) \\
(171)-E u-O(100) \\
(171)-E u-O(372)^{a} \\
(331)-E u-O(371) \\
(100)-E u-O(371) \\
(331)-E u-O(271) \\
(100)-E u-O(271) \\
(371)-E u-O(271) \\
(171)-E u-N(21) \\
(372)^{a}-E u-N(21) \\
(271)-E u-N(21) \\
(171)-E u-N(11) \\
(372)^{a}-E u-N(11) \\
(271)-E u-N(11) \\
(37)^{a}-O(372)^{a}-E u\end{array}$ & $\begin{array}{r}123.7(2) \\
136.0(2) \\
78.8(2) \\
72.1(1) \\
141.2(1) \\
137.0(2) \\
127.3(2) \\
74.5(1) \\
136.5(2) \\
95.7(2) \\
64.3(1) \\
64.7(2) \\
87.7(2) \\
135.8(2) \\
166.7(4)\end{array}$ & $\begin{array}{l}\mathrm{O}(331)-\mathrm{Eu}-\mathrm{O}(100 \\
\mathrm{O}(331)-\mathrm{Eu}-\mathrm{O}(372)^{\mathrm{a}} \\
\mathrm{O}(100)-\mathrm{Eu}-\mathrm{O}(372)^{\mathrm{a}} \\
\mathrm{O}(171)-\mathrm{Eu}-\mathrm{O}(371) \\
\mathrm{O}(372)^{\mathrm{a}}-\mathrm{Eu}-\mathrm{O}(371) \\
\mathrm{O}(171)-\mathrm{Eu}-\mathrm{O}(271) \\
\mathrm{O}(372)^{\mathrm{a}}-\mathrm{Eu}-\mathrm{O}(271) \\
\mathrm{O}(331)-\mathrm{Eu}-\mathrm{N}(21) \\
\mathrm{O}(100)-\mathrm{Eu}-\mathrm{N}(21) \\
\mathrm{O}(371)-\mathrm{Eu}-\mathrm{N}(21) \\
\mathrm{O}(331)-\mathrm{Eu}-\mathrm{N}(11) \\
\mathrm{O}(100)-\mathrm{Eu}-\mathrm{N}(11) \\
\mathrm{O}(371)-\mathrm{Eu}-\mathrm{N}(11) \\
\mathrm{N}(21)-\mathrm{Eu}-\mathrm{N}(11)\end{array}$ & $\begin{array}{r}71.9(2) \\
143.4(1) \\
72.4(1) \\
77.7(2) \\
144.6(1) \\
72.4(2) \\
73.8(1) \\
86.0(2) \\
80.3(2) \\
83.4(2) \\
79.2(2) \\
81.3(2) \\
105.5(2) \\
159.3(2)\end{array}$ \\
\hline
\end{tabular}

a The following symmetry transformation is used to generate equivalent atoms: ${ }^{a} x,-y+3 / 2, z+1 / 2$.

molecules. Furthermore, the crystal displays a 1-D polymeric structure build-up from $\left[\mathrm{Eu}\left(\mathrm{H}_{2} \mathrm{O}\right)(\mathrm{picOH})_{2}\right]^{+}$ structural units linked by $\mathrm{HpicO}^{-}$bridges which hold the europium centers at a long distance of 6.943(1) $\AA$. An ORTEP view showing the atomic connectivities in the building block of the 1-D polymeric chain together with atomic notation scheme adopted is presented in Figure 1a, and the overall geometry of the polymeric chain with europium(III) centers drawn in the polyhedra mode is shown in Figure 1b. Sel ected bond lengths and angles in the metal coordination sphere are given in Table 2. All europium centers are bonded to two nitrogen and six oxygen atoms in a coordination environment that can be described as distorted triangulated dodecahedron (bisphenoid). ${ }^{27} \mathrm{Two} \mathrm{picOH}^{-}$ligands are almost trans making a dihedral angle of $9.1(1)^{\circ}$ and display $\mathrm{N}, \mathrm{O}$ coordination mode with $\mathrm{Eu}-\mathrm{N}$ distances of 2.596(5) and 2.578(5) $\AA$ and $\mathrm{Eu}-\mathrm{O}$ distances of 2.373(4) and $2.410(4) \AA$. The third $\mathrm{H}_{\text {picO- }}{ }^{-}$ligand is coordinated by the oxygen atom of the phenol group and one oxygen atom from the carboxylate group in 0,0 chelation fashion with $\mathrm{Eu}-\mathrm{O}$ distances of 2.393(4) and 2.309(4) $\AA$. The coordination sphere of eight atoms is completed with one water molecule, with a $\mathrm{Eu}-\mathrm{O}$ distance of 2.389(4) $\AA$, and one oxygen atom of a carboxylate group from a second $\mathrm{O}, \mathrm{O}$ chelated $\mathrm{HpicO}^{-}$ligand belonging to the neighboring structural unit. This bridging oxygen is bonded almost linearly to the metal center with a Eu-O bond distance of 2.390(4) $\AA$ and a C-O-Eu angle of $166.7(4)^{\circ}$. From the Cambridge Crystall ographic Data Base $^{28}$ we retrieved nineteen structures having $\mathrm{EuN}_{2} \mathrm{O}_{6}$ coordination polyhedra with $\mathrm{Eu}-\mathrm{N}$ and $\mathrm{Eu}-\mathrm{O}$ distances within a wider range of $2.448-2.655 \AA$ and $2.224-2.510$ $\AA$, respectively.

The charge balance of the molecular formula for complex 1 requires that the three 3-hydroxypicolinate ligands are monoprotonated. Indeed, the final difference Fourier map revealed the unambiguous location of one hydrogen atom bonded to each of the two $\mathrm{picOH}^{-}$

(27) Wells, A. F. Structural Inorganic Chemistry; Clarendon Press: Oxford, 1984; pp 78 and 79. 31. 
Table 3. Dimensions of the Hydrogen Bonds

\begin{tabular}{|c|c|c|c|}
\hline \multirow[b]{2}{*}{ donor-H....acceptor } & \multicolumn{2}{|c|}{ distances $(\AA)$} & \multirow{2}{*}{$\frac{\text { angle (deg) }}{D-H \cdots A^{a}}$} \\
\hline & $H \cdots A^{a}$ & $D \cdots A^{a}$ & \\
\hline $\mathrm{N}(31)-\mathrm{H}(31) \cdots \mathrm{O}(372)$ & $2.30(5)$ & $2.665(5)$ & 104(3) \\
\hline$N(31)-H(31) \cdots O(171)[x, 3 / 2-y,-1 / 2+z]$ & $2.57(6)$ & $3.035(7)$ & $113(5)$ \\
\hline$N(31)-H(31) \cdots O(271)[x, 3 / 2-y,-1 / 2+z]$ & $1.90(5)$ & $2.779(6)$ & 167(6) \\
\hline $\mathrm{O}(100)-\mathrm{H}(101) \cdots \mathrm{O}(300)$ & $1.89(2)$ & $2.702(7)$ & $172(7)$ \\
\hline $\mathrm{O}(100)-\mathrm{H}(102) \cdots \mathrm{O}(200)$ & $1.92(4)$ & $2.712(6)$ & $163(7)$ \\
\hline $\mathrm{O}(131)-\mathrm{H}(131) \cdots \mathrm{O}(172)$ & $1.77(10)$ & $2.551(8)$ & $160(11)$ \\
\hline $\mathrm{O}(200)-\mathrm{H}(201) \cdots \mathrm{O}(272)[1-x, 1 / 2+y, 3 / 2-z]$ & $2.00(6)$ & $2.811(7)$ & 168(6) \\
\hline $\mathrm{O}(200)-\mathrm{H}(202) \cdots \mathrm{O}(300)[1-\mathrm{x}, 2-\mathrm{y}, 2-\mathrm{z}]$ & $1.99(6)$ & $2.792(8)$ & $167(6)$ \\
\hline $\mathrm{O}(231)-\mathrm{H}(231) \cdots \mathrm{O}(272)$ & $1.86(9)$ & $2.610(7)$ & $152(8)$ \\
\hline $\mathrm{O}(300)-\mathrm{H}(301) \cdots \mathrm{O}(371)[\mathrm{x}, 3 / 2-\mathrm{y}, 1 / 2+\mathrm{z}]$ & $2.10(3)$ & $2.892(5)$ & $163(6)$ \\
\hline $\mathrm{O}(300)-\mathrm{H}(302) \cdots \mathrm{O}(400)[x, 3 / 2-y,-1 / 2+z]$ & $1.98(6)$ & $2.778(10)$ & 166(4) \\
\hline $\mathrm{O}(400)-\mathrm{H}(402) \cdots \mathrm{O}(172)$ & $1.89(9)$ & $2.714(10)$ & $173(11)$ \\
\hline
\end{tabular}

${ }^{a} A$ and $D$ denote the acceptors and donors, respectively.

Table 4. Analytical and Spectroscopic Data for Lanthanide Complexes of 3-Hydroxypicolinic Acid and the Free Ligand

\begin{tabular}{|c|c|c|c|c|c|c|c|c|c|c|c|}
\hline \multirow[b]{2}{*}{ compound } & \multicolumn{4}{|c|}{ analysis ${ }^{\mathrm{a}}(\%)$} & \multicolumn{4}{|c|}{ vibrational spectra ${ }^{\mathrm{b}}\left(\mathrm{cm}^{-1}\right)$} & \multicolumn{3}{|c|}{${ }^{1} \mathrm{H} \mathrm{NMR}^{\mathrm{c}}(\delta / \mathrm{ppm})$} \\
\hline & $\mathrm{C}$ & $\mathrm{N}$ & $\mathrm{H}$ & Ln & $v_{\mathrm{as}}\left(\mathrm{CO}_{2}\right)$ & $v(\mathrm{C}-\mathrm{N})$ & $v_{\mathrm{s}}\left(\mathrm{CO}_{2}\right)$ & $v(\mathrm{C}-\mathrm{O})_{\mathrm{h}}$ & $\mathrm{H}_{4}$ & $\mathrm{H}_{5}$ & $\mathrm{H}_{6}$ \\
\hline 3-hydroxypicolinic acid & & & & & $\begin{array}{l}1702 \mathrm{~s} \\
-\end{array}$ & $\begin{array}{l}1608 \mathrm{~s} \\
1612(6)\end{array}$ & $\begin{array}{l}1320 \mathrm{~s} \\
1323(4)\end{array}$ & $\begin{array}{l}1284 \text { vs } \\
1286(2)\end{array}$ & 7.87 & 7.79 & 8.14 \\
\hline$\left[\mathrm{Eu}\left(\mathrm{H}_{2} \mathrm{O}\right)(\mathrm{picOH})_{2}(u-\mathrm{H}\right.$ picO $\left.)\right] \cdot 3 \mathrm{H}_{2} \mathrm{O} \mathbf{1}$ & $\begin{array}{c}32.91 \\
(33.87)\end{array}$ & $\begin{array}{c}6.85 \\
(6.58)\end{array}$ & $\begin{array}{c}3.11 \\
(3.16)\end{array}$ & $\begin{array}{c}23.41 \\
(23.81)\end{array}$ & $\begin{array}{l}1621 \text { vs } \\
1619(1)\end{array}$ & $\begin{array}{l}1590 \text { vs } \\
1596(1)\end{array}$ & $\begin{array}{l}1344 \mathrm{~s} \\
1322(1)\end{array}$ & $\begin{array}{l}1265 \mathrm{~s} \\
1259(2)\end{array}$ & 10.0 & 7.5 & 11.3 \\
\hline$\left[\mathrm{Tb}\left(\mathrm{H}_{2} \mathrm{O}\right)(\mathrm{picOH})_{2}(\mu-\mathrm{H}\right.$ picO $\left.)\right] \cdot 3 \mathrm{H}_{2} \mathrm{O} 2$ & $\begin{array}{c}32.12 \\
(33.50)\end{array}$ & $\begin{array}{c}6.69 \\
(6.51)\end{array}$ & $\begin{array}{c}3.35 \\
(3.12)\end{array}$ & $\begin{array}{c}23.39 \\
(24.63)\end{array}$ & $\begin{array}{l}1623 \text { vs } \\
1626(1)\end{array}$ & $\begin{array}{l}1592 \text { vs } \\
1598(2)\end{array}$ & $\begin{array}{l}1344 \mathrm{~s} \\
1322(1)\end{array}$ & $\begin{array}{l}1265 \mathrm{~s} \\
1259(2)\end{array}$ & 47 & 36 & 57 \\
\hline$\left[\mathrm{Er}\left(\mathrm{H}_{2} \mathrm{O}\right)(\text { picOH })_{2}(\mu-\mathrm{H}\right.$ picO $\left.)\right] \cdot 3 \mathrm{H}_{2} \mathrm{O} 3$ & $\begin{array}{c}32.45 \\
(33.08)\end{array}$ & $\begin{array}{c}6.59 \\
(6.43)\end{array}$ & $\begin{array}{c}3.27 \\
(3.08)\end{array}$ & $\begin{array}{c}25.66 \\
(25.59)\end{array}$ & $\begin{array}{l}1625 \text { vs } \\
1623(1)\end{array}$ & $\begin{array}{l}1594 \text { vs } \\
1597(1)\end{array}$ & $\begin{array}{l}1344 \mathrm{~s} \\
1325(1)\end{array}$ & $\begin{array}{l}1265 \mathrm{~s} \\
1259(2)\end{array}$ & 10.8 & 6.3 & 13.0 \\
\hline
\end{tabular}

${ }^{a}$ Calculated values in parentheses. ${ }^{b}$ Infrared and Raman (in italics) data: vs, very strong; s, strong. ${ }^{c}$ Spectra in $\mathrm{CD}_{3} \mathrm{SO}$ solution.

ligands having $\mathrm{N}, \mathrm{O}$ chelation mode, while the third proton was found to be bonded to the nitrogen of the pyridine ring (for details see above) of the bridging $\mathrm{HpicO}^{-}$ligand. Several intramolecular hydrogen bonds involving the phenolic $\mathrm{OH}$ in $\mathrm{picOH}^{-}$ligands or the protonated pyridinic nitrogen $\mathrm{N}-\mathrm{H}$ and the corresponding carboxylate in $\mathrm{H} \mathrm{picO}^{-}$were found. The dimensions of these hydrogen bonds are given in Table 3 together with other intermolecular hydrogen bonding interactions.

As described above, in the crystal lattice the $\mathrm{H} \mathrm{picO}^{-}$ bridging units act as tridentate ligands and consequently they are the structural motifs that organize the $\left\{\mathrm{Eu}\left(\mathrm{H}_{2} \mathrm{O}\right)(\mathrm{picOH})_{2}(\mu-\mathrm{picOH})\right\}_{n}$ 1-D polymeric chains. These chains run along the $\mathrm{c}$ axis and are located around a $2{ }_{1}$ screw crystallographic axis (Figure $1 b$ ). Furthermore, a detailed analysis of the crystal structure reveals that 1-D dimensional chains are assembled into a 2-D network through an extensive and complex system of hydrogen bonds between the crystallization waters, the coordinated waters, and the remaining donor atoms of the three 3-hydroxypicolinate ligands, including the bridging one. A view of the crystal-packing diagram of 1, down the $\mathrm{c}$ axis, showing the hydrogen bonding interactions is presented in Figure 2 whereas the bond dimensions are listed in Table 3 . The most noticeable structural feature of the hydrogen bond pattern is the formation of six-membered centrosymmetric hexagonal supramolecular rings (zone $\mathbf{A}$ in Figure 2 ) of oxygen atoms held together by hydrogen bonds. The three unique hydrogen bonds include 2 between coordinated oxygen waters and water bridges (distances for $\mathrm{O}-\mathrm{H} \cdots \mathrm{O}$ $1.89(2), 1.92(4) \AA)$, together with one between adjacent water molecules of 1.99(6) $\AA$. In addition, the aromatic rings of bridging ligands of adjacent 1-D polymeric chains are al most parallel, making a dihedral angle of only $4^{\circ}$ and adopting a staggered arrangement (zone $\mathbf{B}$ in Figure 2). The distance between the centroids of the $\pi$ stacking rings is only $3.879 \AA$. Thus, this geometric arrangement suggests that the crystal structure is also stabilized by face-to-face $\pi$ stacking interactions.

Vibrational and NMR Spectra. Infrared and Raman spectroscopic data for 3-hydroxypicolinic acid $(\mathrm{HpicOH})$ and its complexes are shown in Table 4, with tentative assignments based on those found in the literature for $\mathrm{H}$ picOH d-transition metal complexes. ${ }^{13,14}$ The selected bands of the free ligand, namely the carboxylate asymmetric and symmetric stretches, $v_{\text {as }}\left(\mathrm{CO}_{2}\right)$ and $v_{\mathrm{s}}\left(\mathrm{CO}_{2}\right)$, and the $\mathrm{C}-\mathrm{O}$ stretch of the carbon bound to the hydroxyl group, $v(\mathrm{C}-\mathrm{O})_{\mathrm{h}}$, are sensitive to metal coordination as reported for complexes of hydroxybenzoic acids. ${ }^{15,16}$

In the infrared and Raman spectra, the asymmetric mode $v_{\text {as }}\left(\mathrm{CO}_{2}\right)$ shows shifts (up to $83 \mathrm{~cm}^{-1}$ ) to a lower wavenumber on coordination when compared to the free ligand (at $1702 \mathrm{~cm}^{-1}$ ), showing that the ligand is bound to the lanthanide through the carboxylate oxygen. The crystal structure of $\mathbf{1}$ shows that, in fact, two of the picOH ${ }^{-}$ligands are bound through $\mathrm{N}, \mathrm{O}-$-chelation, with a carboxylate oxygen coordinated to the lanthanide, while the third ligand shows O,O-chelation with the carboxylate group also making a bridge to the nearest lanthanide and thus having both carboxylate oxygens coordinated. The symmetric mode $v_{s}\left(\mathrm{CO}_{2}\right)$ shows smaller shifts (up to $24 \mathrm{~cm}^{-1}$ ) to higher wavenumber on coordination when compared to the free ligand (at 1320 $\mathrm{cm}^{-1}$ ). Similar shifts were reported for salicylic acid complexes. ${ }^{16}$

The pyridine $v(\mathrm{C}-\mathrm{N})$ stretch, at $1608 \mathrm{~cm}^{-1}$ for the free ligand, shows shifts up to $18 \mathrm{~cm}^{-1}$, on coordination to the lanthanide ion. These shifts, on both infrared and Raman spectra, show that coordination to the lanthanide ion also involves the nitrogen atom of $\mathrm{HpicOH}$, 

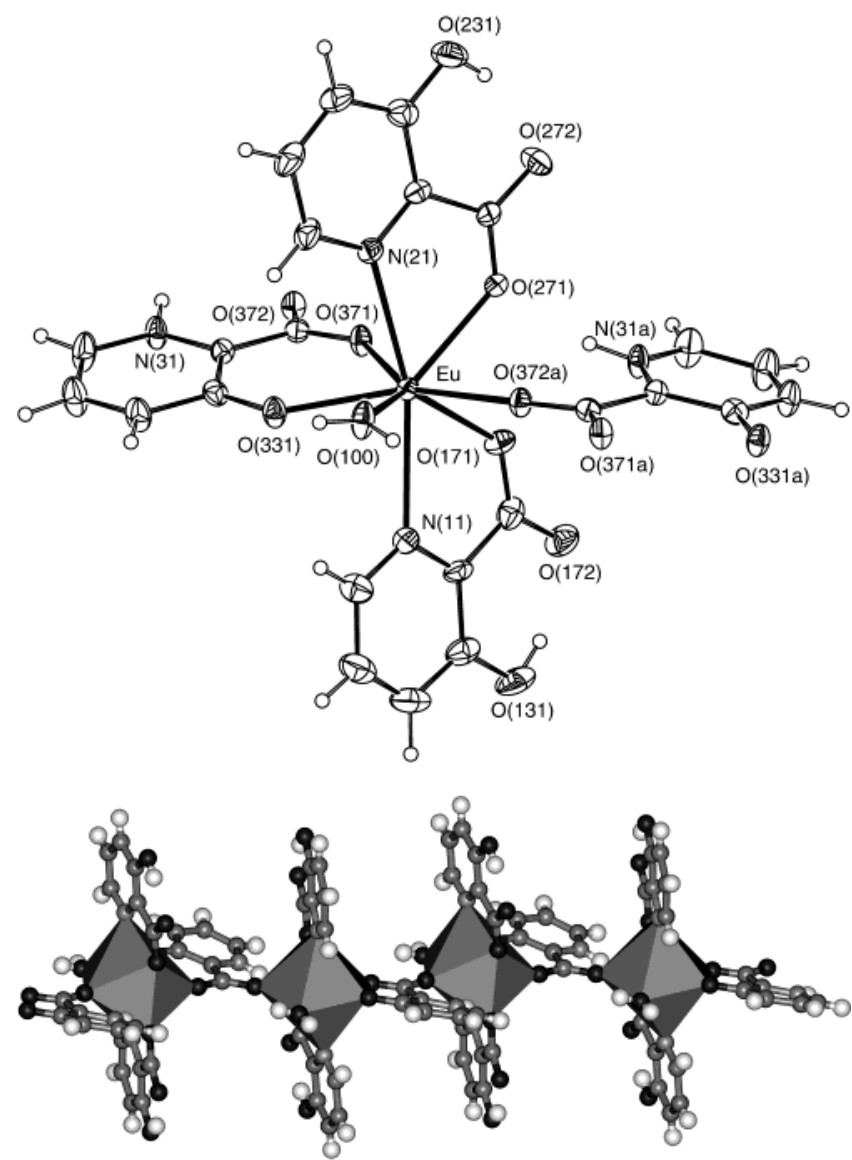

Figure 1. Crystal structure of $\left[\mathrm{Eu}\left(\mathrm{H}_{2} \mathrm{O}\right)(\mathrm{picOH})_{2}(u\right.$ - $\mathrm{H}$ picO $\left.)\right] \cdot$ $3 \mathrm{H}_{2} \mathrm{O}$ 1: (a) ORTEP view of the building unit of $\mathbf{1}$ showing the atomic conectivities, labeling scheme adopted, and the thermal ellipsoids drawn at $30 \%$ of probability level; labels of the carbon atoms are omitted for clarity; and (b) view of the polymeric $\left\{\mathrm{Eu}\left(\mathrm{H}_{2} \mathrm{O}\right)(\mathrm{picOH})_{2}(\mu-\mathrm{picOH})\right\}_{n} 1-\mathrm{D}$ chain down the $\mathrm{C}$ axis with the $\mathrm{Eu}^{3+}$ centers drawn in the polyhedra style.

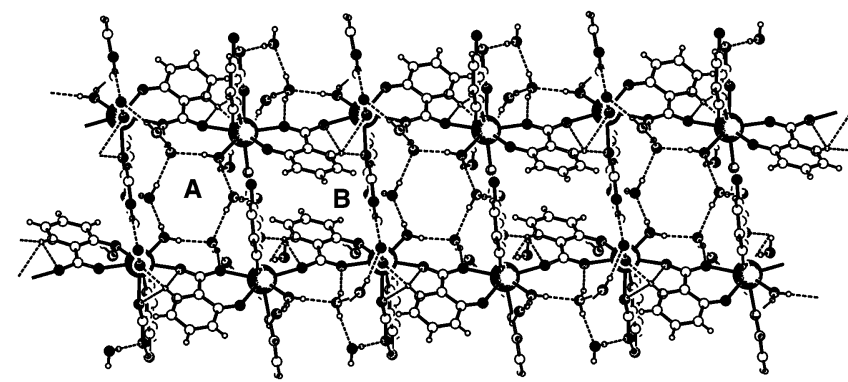

Figure 2. View of the crystal packing diagram of $\mathbf{1}$ down the $c$ axis showing how the $\left\{\mathrm{Eu}\left(\mathrm{H}_{2} \mathrm{O}\right)(\mathrm{picOH})_{2}(\mu \text {-picOH })\right\}_{n} 1-\mathrm{D}$ polymeric chains are assembled by water molecules via hydrogen bond into a 2-D network running along the [100] crystallographic plane.

according to the $\mathrm{N}, \mathrm{O}$-chelation of two of the coordinated $\mathrm{picOH}^{-}$ligands seen in the crystal structure of $\mathbf{1}$. A N,Ochelation has also been reported for Ln complexes with picolinic and di picolinic acids. ${ }^{7}$ Shifts of $19 \mathrm{~cm}^{-1}$ shown in the complexes spectra for the bands assigned to the $v(\mathrm{C}-\mathrm{O})_{\mathrm{h}}$ stretch (at $1284 \mathrm{~cm}^{-1}$ for the hydroxyl group of the free ligand), are possibly due both to the $\mathrm{O}, \mathrm{O}$ chelation of one ligand, and to hydrogen bonding to the adjacent carboxylate group in the other two $\mathrm{picOH}^{-}$ ligands bound through N,O-chelation. The infrared spectra of the lanthanide complexes show a very strong absorption in the region $3000-3500 \mathrm{~cm}^{-1}$, assigned to<smiles>Cc1nc(C(=O)O)c(O)c(C)c1C</smiles>

the stretching vibrations of the $\mathrm{O}-\mathrm{H}$ bonds in (a) the hydroxyl group of the $\mathrm{N}, \mathrm{O}$-chelated $\mathrm{picOH}^{-}$ligand (maximum at $3175 \mathrm{~cm}^{-1}$ ), (b) the coordinated water molecules (maximum at $3260 \mathrm{~cm}^{-1}$ ), and (c) the crystallization water molecules (maximum at $3380 \mathrm{~cm}^{-1}$ ).

The ${ }^{1} \mathrm{H}$ NMR signals for the $\left[\mathrm{Ln}\left(\mathrm{H}_{2} \mathrm{O}\right)(\mathrm{picOH})_{2}(\mu-\right.$ $\mathrm{H}$ picO)] $\cdot 3 \mathrm{H}_{2} \mathrm{O}$ complexes are broad, and relative intensities cannot be discussed. All the Ln compounds reported here show a set of three signals located close to each other (see Chart 1 for labeling and Table 4 for tentative assignments). These resonances are assigned to the three protons of the pyridine ring. Strong shifts can be induced by the lanthanide ion, in particular in the case of the $\mathrm{Tb}(\mathrm{III})$ complex.

The X-ray powder diffraction patterns for complexes $\mathbf{1}, \mathbf{2}$, and $\mathbf{3}$ show that these compounds are isostructural. This, together with the vibrational spectroscopy data, confirms the same type of coordination for all the $\mathrm{Ln}$ complexes reported here.

Photoluminescence Spectra. Figure $3 \mathrm{~A}$ and $\mathrm{B}$ show the room temperature (RT) photoluminescence $(\mathrm{PL})$ spectra for the $\mathrm{HpicOH}$ ligand, $\mathrm{Tb}^{3+}$, and $\mathrm{Eu}^{3+}$ complexes. The sharp lines are assigned to transition between the first excited state $\left({ }^{5} \mathrm{D}_{4}\right.$ and ${ }^{5} \mathrm{D}_{0}$, for $\mathrm{Tb}^{3+}$ and $\mathrm{Eu}^{3+}$, respectively) and the ground multiplet, ${ }^{7} \mathrm{~F}_{6-3}$ and ${ }^{7} \mathrm{~F}_{0-4}$, for $\mathrm{Tb}^{3+}$ and $\mathrm{Eu}^{3+}$, respectively. The large broad band in the green-blue spectral region is also observed in the $\mathrm{PL}$ spectrum of the $\mathrm{H}$ picOH ligand, peaking around $418 \mathrm{~nm}$ (Figure 3A), and may be assigned to the emission from $\pi \pi^{*}$ states of the chelate ring, as reported for terpyridine, ${ }^{29}$ for instance. When the lanthanide ions are coordinated the emission energy of the ligand broad band is altered. In the case of the $\mathrm{Tb}^{3+}$ complex, its maximum intensity position shifts from 418 to $420 \mathrm{~nm}$. This indicates an effective interaction between the terbium ion and the picOH ligand. Moreover, the differences in the relative intensity of this broad band with respect to the $\mathrm{Tb}^{3+}$ and $\mathrm{Eu}^{3+}$ lines ( $F$ igure $3 \mathrm{~A}$ and $\mathrm{B}$ ) indicate that energy transfer occurs between the ligand and the lanthanide ions. As no emission intensity from the ligand could be detected in the $\mathrm{Eu}^{3+}$ complex, the emission spectrum displays only the intra- $4 f^{6}{ }^{5} D_{0} \rightarrow{ }^{7} F_{0-4}$ transitions (Figure $3 B$ ); this energy transfer process seems to be very efficient for that compound. The inset of Figure 3B illustrates this ligand-to-metal energy transfer for the $\mathrm{Eu}^{3+}$ complex. Besides the intra- $4 f^{6}{ }^{7} F_{0} \rightarrow{ }^{5} L_{6},{ }^{5} D_{2,1}$ transitions, the photol uminescence excitation spectrum displays a very large broad band between 320 and $400 \mathrm{~nm}$ associated with the $\mathrm{HpicOH}$ ligand.

The lifetime of the $\mathrm{Eu}^{3+}$ first excited state, $\tau_{\exp }\left({ }^{5} \mathrm{D}_{0}\right)$, was detected at $614 \mathrm{~nm}$ (the more intense $\mathrm{Eu}^{3+}$ emission

(29) Fink, D. W.; Ohnesorge, W. E. J . Phys. Chem. 1970, 74, 72. 

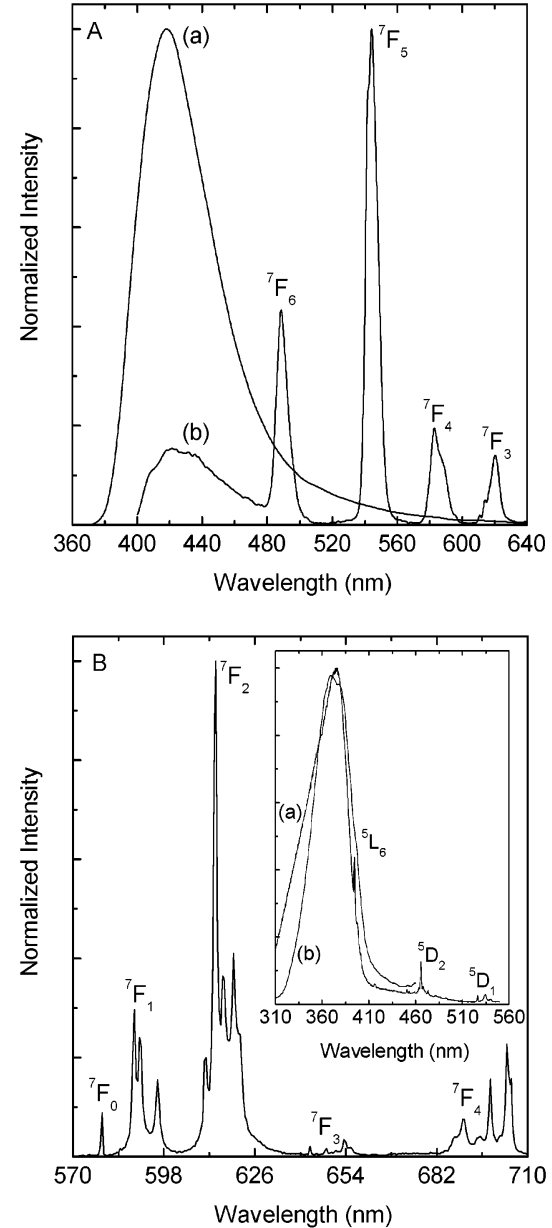

Figure 3. Room-temperature $\mathrm{PL}$ spectra (excited at $325 \mathrm{~nm}$ ) for $\mathrm{A}$ : $\mathrm{H}$ picOH ligand, (a) and $\left[\mathrm{Tb}\left(\mathrm{H}_{2} \mathrm{O}\right)(\mathrm{picOH})_{2}(\mu-\mathrm{H}\right.$ picO)]. $3 \mathrm{H}_{2} \mathrm{O}$, (b). B: $\left[\mathrm{Eu}\left(\mathrm{H}_{2} \mathrm{O}\right)(\text { picOH })_{2}(\mu-\mathrm{H}\right.$ picO $\left.)\right] \cdot 3 \mathrm{H}_{2} \mathrm{O}$. The sharp lines are assigned to the ${ }^{5} \mathrm{D}_{4} \rightarrow{ }^{7} \mathrm{~F}_{6,5,4,3}\left(\mathrm{~Tb}^{3+}\right)$ and ${ }^{5} \mathrm{D}_{0} \rightarrow{ }^{7} \mathrm{~F}_{0,1,2,3,4}$ $\left(\mathrm{Eu}^{3+}\right)$ transitions, respectively. The inset shows the excitation spectra recorded at RT for $\mathrm{H}$ picOH ligand, (a) and $\left[\mathrm{Eu}\left(\mathrm{H}_{2} \mathrm{O}\right)\right.$ $(\mathrm{picOH})_{2}(\mu-\mathrm{H}$ picO $\left.)\right] \cdot 3 \mathrm{H}_{2} \mathrm{O}(\mathrm{b})$, monitored at 420 and $614 \mathrm{~nm}$, respectively.

line) with an excitation wavelength of $395 \mathrm{~nm}$. The decay profile is well reproduced by a single-exponential that reveals a lifetime of $0.481 \pm 0.002 \mathrm{~ms}$.

We can estimate the efficiency, $q$, of the ${ }^{5} \mathrm{D}_{0} \mathrm{Eu}^{3+}$ excited state. Assuming that only nonradiative and radiative processes are essentially involved in the depopulation of the ${ }^{5} \mathrm{D}_{0}$ state, $q$ can be defined as follows:

$$
q=\frac{k_{r}}{k_{r}+k_{n r}}
$$

where $k_{r}$ and $k_{n r}$ are the radiative and the nonradiative transition probabilities, respectively.

The emission intensity, I, taken as the integrated intensity $S$ of the emission curves, for the ${ }^{5} D_{0} \rightarrow{ }^{7} F_{0-4}$ transitions, is expressed by

$$
\mathrm{I}_{\mathrm{i} \rightarrow \mathrm{j}}=\hbar \mathrm{w}_{\mathrm{i} \rightarrow \mathrm{j}} \mathrm{A}_{\mathrm{i} \rightarrow \mathrm{j}} \mathrm{N}_{\mathrm{i}} \equiv \mathrm{S}_{\mathrm{i} \rightarrow \mathrm{j}}
$$

where $i$ and $j$ represent the initial $\left({ }^{5} D_{0}\right)$ and final levels $\left({ }^{7} F_{0-4}\right)$, respectively, $\hbar w_{i \rightarrow j}$ is the transition energy, $A_{i \rightarrow j}$ corresponds to the Einstein's coefficient of spontaneous emission, and $\mathrm{N}_{\mathrm{i}}$ is the population of the ${ }^{5} \mathrm{D}_{0}$ emitting level. 30,31 The radiative contribution may be calculated from the relative intensities of the ${ }^{5} D_{0} \rightarrow{ }^{7} F_{0-4}$. The branching ratio for the ${ }^{5} D_{0} \rightarrow{ }^{7} F_{5,6}$ transitions must be neglected as they are not observed experimentally. Therefore, we can ignore their influence in the depopulation of the ${ }^{5} D_{0}$ excited state. Because the ${ }^{5} D_{0} \rightarrow{ }^{7} F_{1}$ transition can be considered as a reference, due to its di polar magnetic nature $\mathrm{k}_{\mathrm{r}}$ can be calculated as follows:

$$
\mathrm{k}_{\mathrm{r}}=\mathrm{A}_{0 \rightarrow 1} \frac{\hbar \omega_{0 \rightarrow 1}}{\mathrm{~S}_{0 \rightarrow 1}} \sum_{\mathrm{J}=0}^{4} \frac{\mathrm{S}_{0-\mathrm{J}}}{\hbar \omega_{0-\mathrm{J}}}
$$

where $A_{0-1}$ is the Einstein's coefficient of spontaneous emission between the ${ }^{5} D_{0}$ and the ${ }^{7} F_{1}$ Stark levels. The ${ }^{5} D_{0} \rightarrow{ }^{7} F_{1}$ transition does not depend on the local ligand field seen by $\mathrm{Eu}^{3+}$ ions and thus may be used as a reference for the whole spectrum, $A_{0-1} \approx 50 \mathrm{~s}^{-1.32} \mathrm{We}$ found a $\mathrm{q}$ value of $\approx 13.5 \%$ for the $\mathrm{Eu}^{3+}$ emission in the $\left[\mathrm{Eu}\left(\mathrm{H}_{2} \mathrm{O}\right)(\mathrm{picOH})_{2}(\mu-\mathrm{H}\right.$ picO $\left.)\right] \cdot 3 \mathrm{H}_{2} \mathrm{O}$ complex. The corresponding value of $\mathrm{k}_{\mathrm{r}}$ is $0.281 \mathrm{~ms}^{-1}$.

$\left[\mathrm{Ln}\left(\mathrm{H}_{2} \mathrm{O}\right)(\mathrm{picOH})_{2}(u-\mathrm{HpicO})\right] \cdot 3 \mathrm{H}_{2} \mathrm{O} / \mathrm{SiO}_{2}$ Nanocomposite Materials. It was found that complex $\mathbf{1}$ can be dispersed within amorphous silica. There is a particular interest in making this type of nanocomposite because it will allow cast pieces of a luminescent material to be fabricated using the sol-gel method. The preparation of such a composite involves the synthesis of colloidal $\mathrm{SiO}_{2}$ in the presence of the $\mathrm{Eu}(\mathrm{III})$ complex $\mathbf{1}$, using an adaptation of the Stöber method. ${ }^{21}$ Figure 4 shows the SEM images of $\mathrm{SiO}_{2}$ particles prepared in the absence (a) or in the presence (b) of complex $\mathbf{1}(\mathrm{Eu} /$ $\mathrm{SiO}_{2}$ composite B). As expected, this method led to welldefined spherical $\mathrm{SiO}_{2}$ sub-micrometric particles in both cases, although a slight agglomeration of the particles occurred when the complex was present. The presence of the complex clearly has an influence on the particles size distribution; with the average diameter of the particles decreasing from $472 \pm 27 \mathrm{~nm}$ to $127 \pm 9 \mathrm{~nm}$. It is well-known that colloidal $\mathrm{SiO}_{2}$ forms threedimensional networks involving chemical reactions at the surface. ${ }^{33}$ Several experimental parameters have been reported to have a strong influence on the type of $\mathrm{SiO}_{2}$ obtained and in particular on its morphological properties. ${ }^{33}$ Thus, the presence of chemical species which may interact with the $\mathrm{SiO}_{2}$ surface can lead to noticeable morphological modifications. The difference observed on the $\mathrm{SiO}_{2}$ particles size distribution (Figure 4) can be related to particle growth inhibition due to the presence of the complex at the $\mathrm{SiO}_{2}$ surfaces. Although complex $\mathbf{1}$ is very soluble in DMSO, which was used in this preparation, there is also the possibility that such complex species act as nucleation centers for the $\mathrm{SiO}_{2}$ growth, therefore increasing the total number of particles and leading to a decrease in the average diameter and standard deviation. The infrared spectra of the $\mathrm{SiO}_{2}$ particles prepared in the presence of the complex $\mathbf{1}$ (both $\mathrm{Eu} / \mathrm{SiO}_{2}$ composites $\mathbf{A}$ and $\mathbf{B}$ ) show

(30) Malta, O. L.; Couto dos Santos, M. A.; Thompson, L. C.; Ito, N. K. J . Lumin. 1996, 69, 77.

(31) Malta, O. L.; Brito, H. F.; Menezes, J . F. S.; Gonçalves e Silva, F. R.; Alves, S., J r.; Farias, F. S., J r.; Andrade, A. V. M. J . Lumin. 1997, 75, 255

(32) Hazenkamp, M. F.; Blasse, G. Chem. Mater. 1990, 2, 105.

(33) Iler, R. K. The Chemistry of Silica; Wiley-Interscience: New York, 1979. 

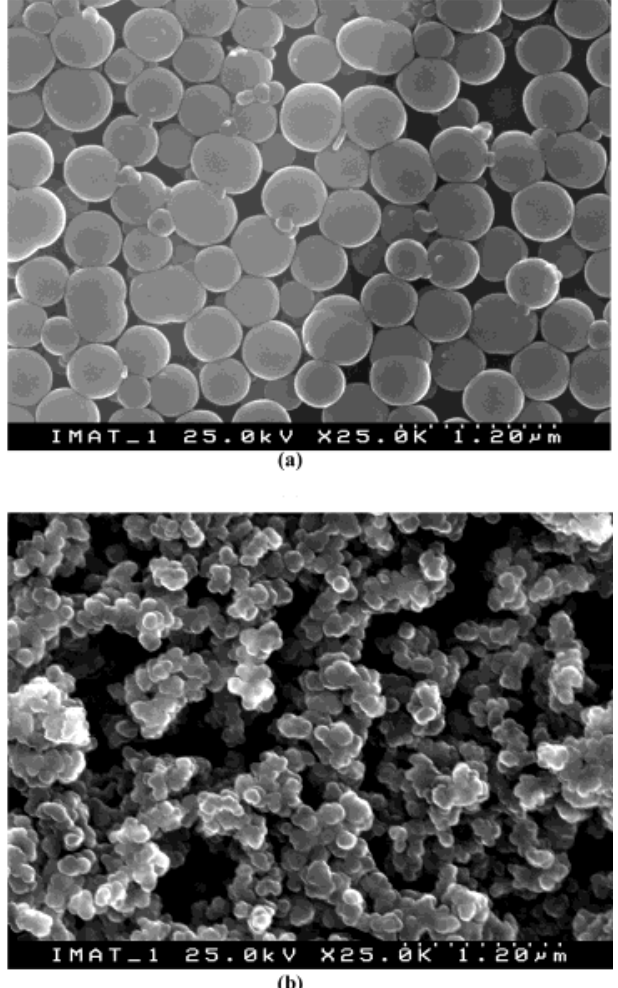

(b)

Figure 4. $\mathrm{SEM}$ images of $\mathrm{SiO}_{2}$ particles prepared in the absence (a) or in the presence (b) of the $\left[\mathrm{Eu}\left(\mathrm{H}_{2} \mathrm{O}\right)(\mathrm{picOH})_{2}(\mu\right.$ $\mathrm{H}$ picO)] $\cdot 3 \mathrm{H}_{2} \mathrm{O}$ complex (Eu/SiO${ }_{2}$ composite $\left.\mathrm{B}\right)$.

bands at 1637 and $1593 \mathrm{~cm}^{-1}$, assigned to the $v_{\text {as }}\left(\mathrm{CO}_{2}\right)$ and $v(\mathrm{C}-\mathrm{N})$ modes of $\mathbf{1}$ (Table 4); other characteristic bands of this complex are also seen at 1411 and 1467 $\mathrm{cm}^{-1}$. The bands assigned to the $\mathrm{Eu}(\mathrm{III})$ complex $\mathbf{1}$ in the infrared spectrum of the $\mathrm{Eu} / \mathrm{SiO}_{2}$ composite $\mathbf{A}$ show a stronger intensity than those observed in the composite B spectrum, which suggests a less amount of complex in B possibly due to the treatment with $\mathrm{NH}_{4} \mathrm{OH}$ used in its preparation. The hydroxyl stretching region at $3500-3700 \mathrm{~cm}^{-1}$ and the region at $1260-1290 \mathrm{~cm}^{-1}$ for the $v(\mathrm{C}-\mathrm{O})_{\mathrm{h}}$ modes, are dominated by the silica strong absorption bands.

The $\left[\mathrm{Eu}\left(\mathrm{H}_{2} \mathrm{O}\right)(\text { picOH })_{2}(u\right.$ - $\mathrm{H}$ picO $\left.)\right] \cdot 3 \mathrm{H}_{2} \mathrm{O} / \mathrm{SiO}_{2}$ particles $\left(\mathrm{Eu} / \mathrm{SiO}_{2}\right.$ composite $\left.\mathbf{A}\right)$ formed a rigid gel on standing in the reaction vessel for long times. This is due to the formation of a polymeric network following condensation reactions at the silica surfaces; finally, a solid monolith was obtained by slow evaporation of the solvent from the gel. Figure 5 displays the PL spectrum of this monolith, herein referred as the $\mathrm{Eu} / \mathrm{SiO}_{2}$ composite $\mathbf{A}$. A series of intra- $4 f^{6}$ lines, assigned to the ${ }^{5} D_{0} \rightarrow{ }^{7} F_{0-4}$ transitions, is observed, together with the presence of the ligand band, peaking around $420 \mathrm{~nm}$. The ligand emission, although with lower relative intensity, with respect to the ion lines, when compared to the spectra of the $\mathrm{Tb}^{3+}$ complex (Figure 3 ), suggests that in the composite $\mathbf{A}$ the ligand-to-metal energy transfer is less efficient than that in $\left[\mathrm{Eu}\left(\mathrm{H}_{2} \mathrm{O}\right)(\mathrm{picOH})_{2}(u-\mathrm{H}\right.$ picO $\left.)\right] \cdot 3 \mathrm{H}_{2} \mathrm{O}$.

When we compare the emission spectrum of the composite $\mathbf{A}$ with the one characteristic of the precursor complex (F igures $3 \mathrm{~b}$ and 5), changes are observed in the energy, maximum splitting, and profile of the ${ }^{5} D_{0} \rightarrow$ ${ }^{7} \mathrm{~F}_{0-4}$ transitions. The energy of the ${ }^{5} \mathrm{D}_{0} \rightarrow{ }^{7} \mathrm{~F}_{0}$ line and its full width at half-maximum (fwhm), for instance,

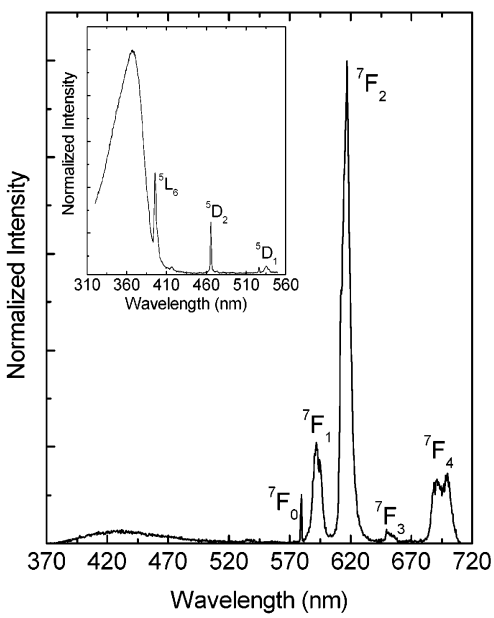

Figure 5. Room-temperature $\mathrm{PL}$ spectra (excited at $325 \mathrm{~nm}$ ) for the $\left[\mathrm{Eu}\left(\mathrm{H}_{2} \mathrm{O}\right)(\mathrm{picOH})_{2}(u-\mathrm{H}\right.$ picO $\left.)\right] \cdot 3 \mathrm{H}_{2} \mathrm{O} / \mathrm{SiO}_{2}$ nanocomposite A. The sharp lines correspond to the ${ }^{5} \mathrm{D}_{0} \rightarrow^{7} \mathrm{~F}_{0,1,2,3,4}$ transitions, and the large broad band (less intense relative to the intra$4 \mathrm{f}^{6}$ lines) is ascribed to the ligands emission. The inset shows the corresponding RT excitation spectrum, monitored at 617 $\mathrm{nm}$

increase for the $\mathrm{E}^{3+}{ }^{3+}$ based composite $\mathbf{A}$, from 17251.39 \pm 0.04 to $17259.23 \pm 0.10 \mathrm{~cm}^{-1}$ and from $3.96 \pm 0.07$ to $25.75 \pm 0.24 \mathrm{~cm}^{-1}$, respectively. M oreover, the localfield splitting of the ${ }^{5} D_{0} \rightarrow{ }^{7} F_{1,2}$ transitions in three and five Stark components, respectively, is much more evident in the $\left[\mathrm{Eu}\left(\mathrm{H}_{2} \mathrm{O}\right)(\mathrm{picOH})_{2}(u-\mathrm{H}\right.$ picO $\left.)\right] \cdot 3 \mathrm{H}_{2} \mathrm{O} \mathrm{com}-$ plex. However, the number of Stark components detected for the ${ }^{5} \mathrm{D}_{0} \rightarrow{ }^{7} \mathrm{~F}_{1-4}$ transitions in both spectra indicate that the $\mathrm{Eu}^{3+}$ ions occupy a very low site symmetry without inversion center, according to the high intensity of the ${ }^{5} D_{0} \rightarrow{ }^{7} F_{2}$ transition.

The ${ }^{5} \mathrm{D}_{0}$ lifetime was measured around the $\mathrm{Eu}^{3+}$ more intense line $(616.9 \mathrm{~nm})$ with an excitation wavelength of $395 \mathrm{~nm}$, and the decay profile is also well reproduced by a single-exponential revealing a lifetime of $0.525 \pm$ $0.006 \mathrm{~ms}$. The radiative transition probability for the $\mathrm{Eu}^{3+}$-based composite $\mathbf{A}$ also increases, relative to the precursor complex, and, therefore, a greater efficiency of the ${ }^{5} \mathrm{D}_{0} \mathrm{Eu}^{3+}$ excited state is found for the composite, $q \approx 20 \%$ (the corresponding value of $\mathrm{k}_{\mathrm{r}}$ is $0.396 \mathrm{~ms}^{-1}$ ). We should note that this increase in the ${ }^{5} D_{0}$ emission efficiency is achieved despite the less efficient ligandto-metal energy transfer process, as stated above.

All the photoluminescent results confirm the presence of the $\mathrm{Eu}^{3+}$ complex in the final $\mathrm{SiO}_{2}$ material and demonstrate the potential of the chemical method reported here to yield high luminescent composites. Moreover, the differences on the energy, profile, and fwhm of the ${ }^{5} D_{0} \rightarrow{ }^{7} F_{0-4}$ transitions, and on the ${ }^{5} D_{0}$ lifetime between the two materials, clearly indicate modifications in the $\mathrm{Eu}^{3+}$ local environment as the $\left[\mathrm{Eu}\left(\mathrm{H}_{2} \mathrm{O}\right)(\mathrm{picOH})_{2}(u\right.$ - $\mathrm{H}$ picO $\left.)\right] \cdot 3 \mathrm{H}_{2} \mathrm{O}$ complex is dispersed within the silica gel. This conclusion will be quantitatively stressed by calculating the experimental intensity parameters $\Omega_{2}$ and $\Omega_{4}$.

Usually the experimental intensity parameters are obtained from absorption data. However, in the case of $\mathrm{Eu}^{3+}$ the pure magnetic dipolar character displayed by the ${ }^{5} D_{0} \rightarrow{ }^{7} F_{1}$ transition allows the determination of the intensity parameters from emission spectra. In addition, the electric dipolar ${ }^{5} D_{0} \rightarrow{ }^{7} F_{2,4,6}$ transitions 
depend only on the $U^{(2)}, U^{(4)}$, and $U^{(6)}$ reduced matrix elements, respectively, which allows the evaluation of the experimental intensity $\Omega_{2,4,6}$ parameters directly from emission data. ${ }^{30,31,34}$ On the basis of the luminescence spectra for the $\left[\mathrm{Eu}\left(\mathrm{H}_{2} \mathrm{O}\right)(\mathrm{picOH})_{2}(u-\mathrm{H}\right.$ picO $\left.)\right] \cdot 3 \mathrm{H}_{2} \mathrm{O}$ and $\left[\mathrm{Eu}\left(\mathrm{H}_{2} \mathrm{O}\right)(\mathrm{picOH})_{2}(u-\mathrm{H}\right.$ picO $\left.)\right] \cdot 3 \mathrm{H}_{2} \mathrm{O} / \mathrm{SiO}_{2}$ (Figure 5) the experimental intensity parameters $\Omega_{2}$ and $\Omega_{4}$ were determined using the ${ }^{5} \mathrm{D}_{0} \rightarrow{ }^{7} \mathrm{~F}_{2}$ and ${ }^{5} \mathrm{D}_{0} \rightarrow{ }^{7} \mathrm{~F}_{4}$ transitions, respectively. The $A_{i} \rightarrow$ j Einstein coefficient is given by the foll owing:30,31,34

$$
\mathrm{A}_{i \rightarrow j}=\frac{4 \mathrm{e}^{2} \omega^{3}}{3 \hbar c^{3}} \frac{1}{2 \mathrm{~J}+1} \chi \sum_{\lambda} \Omega_{\lambda}\left\langle^{7} \mathrm{~F}_{\jmath}\left\|U^{(\lambda)}\right\|^{5} \mathrm{D}_{0}\right\rangle^{2}
$$

where $\omega$ is the frequency of the transition and $\chi=\mathrm{n}_{0}\left(\mathrm{n}_{0}{ }^{2}\right.$ $+2)^{2} / 9$, a Lorentz local field correction for the index of refraction $\mathrm{n}_{0}$ of the medium. The reduced matrix elements in eq 4 were taken from Carnall et al. ${ }^{35}$ and an average index of refraction equal to 1.5 was used. $30,31,34$ The $\Omega_{6}$ intensity parameter was not determined because the ${ }^{5} D_{0} \rightarrow{ }^{7} F_{6}$ transition could not be experimentally detected. This stresses, therefore, that $\Omega_{6}$ is not important here. The obtained values (in units of $10^{-20}$ $\mathrm{cm}^{2}$ ) are 14.1 and $20.5, \Omega_{2}$, and 7.8 and 13.0, $\Omega_{4}$, for $\left[\mathrm{Eu}\left(\mathrm{H}_{2} \mathrm{O}\right)(\text { picOH })_{2}(u-\mathrm{H}\right.$ picO $\left.)\right] \cdot 3 \mathrm{H}_{2} \mathrm{O}$ and $\left[\mathrm{Eu}\left(\mathrm{H}_{2} \mathrm{O}\right)(\mathrm{picOH})_{2}\right.$ $(u-\mathrm{H}$ picO) $] \cdot 3 \mathrm{H}_{2} \mathrm{O} / \mathrm{SiO}_{2}$, respectively.

The interpretation of the physical meaning of the phenomenol ogical J udd-Ofelt intensity parameters still remains a controversial matter for discussion. There have been many attempts in the literature to relate the observed variations with some specific ligand field effects. ${ }^{36} \Omega_{2}$ variations are usually related to the degree of covalency in the lanthanide-first coordination shell interaction. ${ }^{30,31,36-38}$ In the sense of the dynamic coupling contribution to the total intensity, ${ }^{38}$ the polarization of the ligand field induces stronger lanthanideligand bonds and an increase in electric dipolar transitions for noncentrosymmetric ligand fields. On the other hand, $\Omega_{4,6}$ parameters have been related together to bulk properties of the lanthanide-based hosts (viscosity, for instance). $30,31,36,37$ There is no theoretical prediction for this sensibility to macroscopic properties, but empirical variations seem to suggest some kind of relationship.

Comparing the values found for the precursor complex and for the $\mathrm{Eu}^{3+}$-based composite $\mathbf{A}$, we note an increase in both values (by a factor of 1.5) as the complex is dispersed within the silica network. This seems to point out that there is an appreciable variation both on the polarizability of the first coordination shell for the composite and that the steric effects are more significant in this compound, as expected if we are explicitly assuming the $\mathrm{Eu}^{3+}$ coordination to the surface of the spherical $\mathrm{SiO}_{2}$ sub-micrometric particles via silanol groups.

(34) Carlos, L. D.; Messaddeq, Y.; Brito, H. F.; Sá-Ferreira, R. A.; de Zea Bermudez, V.; Ribeiro, S. J . L. Adv. Mater. 2000, 12, 594.

(35) Carnall, W. T.; Crosswhite, H.; Crosswhite, H. M. Energy Structure and Transition Probabilities of the Trivalent Lanthanides in LaF 3 ; Argonne National Laboratory Report, unnumbered; 1977.

(36) Reisfeld, R.; J örgensen, C. K. In Handbook on the Physics and Chemistry of RareEarths; Gschneidner, K. A., Eyring, L., Eds.; N orthHolland: Amsterdam, The Netherlands, 1987; Vol. 9, Ch. 58, and references therein.

(37) Oomen, E. W. J . L.; van Dongen, A. M. A. J . Non-Cryst. Solids 1989, 111, 205

(38) J udd, B. R. J . Chem. Phys. 1979, 70, 4830.
Next, a possible $\mathrm{Eu}^{3+}$-first coordination shell in the $\mathrm{Eu} / \mathrm{SiO}_{2}$ composite $\mathbf{A}$ is discussed using the energy shift of the ${ }^{5} \mathrm{D}_{0} \rightarrow{ }^{7} \mathrm{~F}_{0}$ transition, with respect to the energy calculated for gaseous $\mathrm{Eu}^{3+}$, and the phenomenol ogical evaluation of the number of water molecules coordinated to the metal ion, $\mathrm{n}_{\mathrm{w}}$.

The red-shift observed in the ${ }^{5} D_{0} \rightarrow{ }^{7} F_{0}$ energy, with respect to the energy cal culated for gaseous $\mathrm{E} \mathrm{u}^{3+}$ (17374 $\left.\mathrm{cm}^{-1}\right), 34,39,40$ is related to the nature of the first coordination shell through the following phenomenological equation:

$$
\begin{array}{r}
\Delta \mathrm{E} \equiv \mathrm{E}\left({ }^{5} \mathrm{D}_{0} \rightarrow{ }^{7} \mathrm{~F}_{0}\right)_{\text {complex }}-\mathrm{E}\left({ }^{5} \mathrm{D}_{0} \rightarrow{ }^{7} \mathrm{~F}_{0}\right)_{\text {gaseous }}= \\
\mathrm{C}_{\mathrm{N}}\left(\mathrm{n}_{1} \delta_{1}+\ldots+\mathrm{n}_{\mathrm{j}} \delta_{\mathrm{j}}\right)
\end{array}
$$

in which $C_{N}$ is an adjustable coefficient associated with the total number of $\mathrm{Eu}^{3+}$ first-neighbors, $n_{j}$ is the number of type $\mathrm{j}$ atoms in the first coordination shell, and $\delta_{\mathrm{j}}$ is an adjusted parameter which measures the tendency of an atom to bond covalently to the $\mathrm{Eu}^{3+}$ cation. ${ }^{39}$ Attending to the X-ray data for complex $\mathbf{1}$, a $\mathrm{Eu}^{3+}$ first coordination shell composed of four charged carboxylate oxygens, OT, two amine nitrogen atoms, NT, one water molecule, OW, and one hydroxyl oxygen, $\mathrm{OH}$, we found a ${ }^{5} \mathrm{D}_{0} \rightarrow{ }^{7} \mathrm{~F}_{0}$ energy shift of $-121.9 \pm 3$ $\mathrm{cm}^{-1}$, very close to the experimental value of $-122.2 \pm$ $0.7 \mathrm{~cm}^{-1}$. The corresponding experimental energy shift found for the $\mathrm{Eu}^{3+}$-based composite $\mathbf{A}$ is $-114.8 \pm 0.7$ $\mathrm{cm}^{-1}$.

Horrocks and Sudnick suggested that the number of water molecules coordinated to the metal ion could be evaluated according to the empirical formula ${ }^{41}$

$$
\mathrm{n}_{\mathrm{w}}=1.05\left(\mathrm{k}_{\exp }-\mathrm{k}_{\mathrm{r}}\right)
$$

where $k_{\exp }$ is the total transition probability, $k_{\exp }=1 / \tau_{\exp }$ $=\mathrm{k}_{\mathrm{r}}+\mathrm{k}_{\mathrm{nr}}$. We can use $\mathrm{k}_{\mathrm{r}}$ substituted for the value obtained in $\mathrm{D}_{2} \mathrm{O}$, as originally proposed. ${ }^{11}$ We found that the number of water molecules belonging to the $\mathrm{Eu}^{3+}$ first coordination shell is similar for both the complex and the nanocomposite, $1.9 \pm 0.5$ and $1.6 \pm 0.5$, respectively. Therefore, on the basis of this result and the energy shift of the ${ }^{5} D_{0} \rightarrow{ }^{7} F_{0}$ transition, we suggest that in the nanocomposite the complex is bound to the silica surface via silanol groups, possibly displacing one bridging carboxylate group from the $\mathrm{Eu}^{3+}$ first coordination shell. The predicted value of eq 5 for a $\mathrm{Eu}^{3+}$ first coordination shell involving 3 OT, 2 NT, 1 OW, and 2 $\mathrm{OH}$ is $-116.0 \pm 3.0 \mathrm{~cm}^{-1}$, very close to the experimental value.

\section{Conclusions}

Novel luminescent composite materials have been prepared by a sol-gel method. The materials consist of $\mathrm{a} \mathrm{SiO}_{2}$ matrix that hosts an anchored $\mathrm{Eu}(\mathrm{III})$ complex with coordinated 3-hydroxypicolinateligands, $\left[\mathrm{Eu}\left(\mathrm{H}_{2} \mathrm{O}\right)\right.$ $(\text { picOH })_{2}(\mu-\mathrm{H}$ picO $\left.)\right] \cdot 3 \mathrm{H}_{2} \mathrm{O}$ 1. The X-ray crystal structure of $\mathbf{1}$ shows two picOH${ }^{-}$ligands coordinated by $\mathrm{N}, \mathrm{O}-$

(39) Horrocks, W. D., J r.; Sudnick, W. D. R. Acc. Chem. Res. 1981 12,384

(40) Frey, S. T.; Horrocks, W. D. W., J r. Inorg. Chim. Acta 1995, 229, 383

(41) Carlos, L. D.: Sá-Ferreira, R. A.; de Zea Bermudez, V.; Molina, C.; Bueno, L. A.; Ribeiro, S. J . L. Phys. Rev. B 1999, 60, 10042. 
chelation, and the third ligand bound through 0,0 chelation with the carboxylate group making a bridge to the nearest lanthanide, one water molecule and a hydroxyl group completes the Eu(III) first coordination shell; the $\mathrm{Tb}$ (III) and $\mathrm{Er}(\mathrm{III})$ complexes are isostructural as shown by $\mathrm{X}$-ray powder diffraction and the spectroscopy results. The Eu(III) complex 1 was dispersed within a silica matrix by the in situ preparation of silica nanoparticles using the Stöber method. The photoluminescent features of the composite, namely the experimental ${ }^{5} D_{0}$ lifetime, the energy of the ${ }^{5} D_{0} \rightarrow{ }^{7} F_{0}$ transition, and the calculated values for the experimental intensity parameters, strongly suggest that the $\mathrm{Eu}^{3+}$ are coordinated to the surface of the nanoparticles. To better understand the composite's properties, the preparation of a series of $\mathrm{SiO}_{2}$ nanocomposites incorporating other Ln complexes with aromatic ambidentate ligands is in progress.

Acknowledgment. P.S.-S. thanks the University of Aveiro for a Ph.D. research grant. R.A.S.F. thanks the Fundação para a Ciência e Tecnologia (FCT) for grant PRAXIS/BD/18404/98. We thank the FCT for financial support (grant contracts POCTI/35378/QUI/00 and POCTI/33653/CTM/00) as supported by FEDER. We thank the EPSRC and the University of Reading for funds for the I mage Plate system.

Supporting Information Available: Crystallographic data (CIF). This material is available free of charge via the Internet at http://pubs.acs.org.

CM 021188j 